\title{
IMPROVEMENT OF FIRE REACTION AND MOULD GROWTH RESISTANCE OF A NEW BIO-BASED THERMAL INSULATION MATERIAL
}

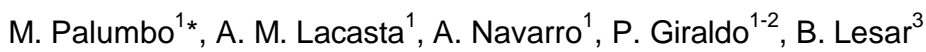 \\ ${ }^{1}$ Universitat Politècnica de Catalunya, Barcelona School of Building Construction, Av. Doctor Marañon 44, \\ 08028 Barcelona, Spain \\ ${ }^{2}$ CTFC - Forest Sciences Centre of Catalonia, Ctra. de St. Llorenç Km 2, Solsona, Spain. \\ ${ }^{3}$ University of Ljubljana, Biotechnical Faculty, Department of Wood Science and Technology, Jamnikarjeva \\ 101, Si-1000 Ljubljana, Slovenia \\ *Corresponding author; e-mail: mariana.palumbo@upc.edu
}

\begin{abstract}
In the present paper, the performance of an innovative thermal insulation rigid board is evaluated in terms of fire behaviour and fungal resistance. The board is based on vegetal pith and a natural gum (corn pith and sodium alginate) and it is completely compostable. This new composite was developed in previous work. Here boric acid, aluminium hydroxide and ammonium polyphosphate are used as fire retardants and montan wax, acetic acid and lactic acid are used as water repellent and fungicides respectively. Interactions between these different treatments is investigated. Both flaming and smouldering combustion processes of the different formulations are evaluated by small-scale techniques which include pyrolysis microcalorimetry and thermogravimetric analysis. A medium-scale device is also designed in order to study the impact of the different additives to the smouldering kinetics. Fire behaviour tests show that good improvement is obtained, both in flaming and smouldering combustion when boric acid is added. Although smouldering is not avoided in any case, the addition of $8 \%$ of boric acid or aluminium hydroxide slows down the speed of combustion propagation. The effect of the different additives on the moisture content and mould growth at $97 \% \mathrm{RH}$ and $27^{\circ} \mathrm{C}$ is analysed. Under such severe conditions none of the additives is able to prevent mould growth, with the exception of boric acid. None or marginal mould growth was observed on samples containing $8 \%$ of boric acid although moisture content was higher than the other cases.
\end{abstract}

Keywords:

Corn pith, maize, alginate, thermal insulation, fire behaviour, smouldering combustion, fungal attack.

\section{INTRODUCTION}

The use of low embodied carbon and locally available building materials for energy refurbishment is gaining interest in the recent years as the sector is moving towards new approached to energy efficient design.

The use of crop by-products as raw materials in building insulation products might contribute in this respect [Korjenic 2011; Madurwar 2013; Mohanty 2000]. Together with the good hygrothermic properties of these natural materials, their availability from renewable resources is considered as one of their main advantages compared with other petroleumderived insulations [Palumbo 2014]. In addition, the use of crop by-products has a positive environmental impact because implies the revaluation of accumulated agricultural waste. All of these beneficial aspects encourage their use in building insulation, but it is necessary to analyse their potential response under real conditions. In particular resistance to fungal attack and fire behaviour are the two main issues to be considered before establish the feasibility of their use. In this research, the performance of an innovative thermal insulation rigid board is evaluated. The board is based on corn pith agglutinated with sodium alginate [Palumbo 2015; Palumbo 2014]. Here, the corn pith is pre-treated with different substances i.e. boric acid, aluminium hydroxide, montan wax, acetic acid and lactic acid before forming the board in order to improve the fire reaction and fungal resistance of the material.

\subsection{Fire reaction}

Several authors have analysed the thermal degradation and flammability of different natural fibres and composites that include such fibres [Alvarez 2004; Dorez 2013; Yao 2008]. In a previous paper [Palumbo 2015], the fire behaviour of experimental insulation materials based on food crop by-products (rice husk, barley straw and corn pith) and natural binders (sodium alginate and corn starch) was evaluated. Both, small-scale pyrolysis combustion flow calorimetry (PCFC) and fire reaction tests indicated that the fire properties of the six experimental natural insulation materials were very favourable when compared with other organic foamy materials commonly used in building insulation, such as polystyrene and polyurethane. The use of alginate as a binder improved the properties of the crop by-product alone, especially in the case of corn pith, where both the total heat release HR and the peak of heat release rate PHRR were reduced by $30 \%$.

In addition to flaming combustion, that take place in gas phase between the generated volatile gases and oxygen, smouldering was also observed in corn pith based panels [Palumbo 2015]. Smouldering is a slow flameless form of combustion that is sustained by the exothermic surface reaction between solid fuel and oxygen. This type of combustion is characteristic of porous materials which form a solid carbonaceous char when heated, and is frequently observed in cellulosic materials [Ohlemiller 1983; Dougal 1998; Hagen 2011]. Smouldering propagation is about ten times slower than flame spread over a solid. In spite of its weak combustion characteristics, smouldering is a significant fire hazard. The initiation and propagation of smouldering are controlled by several interrelated factors as surface area per unit mass 
of fuel, permeability and thermal insulation [Drysdale 1998; Shafizadeh 1979; Moussa 1976]. He et al. [He 2009] investigated the reaction heat of agro-stalks using a simultaneous thermal analyser (STA), in air, using a crucible with lid. Based on the analysis of the DSC curves, oxidative polymer degradation heat and char oxidation heat were obtained from experimental data. Ohlemiller et al.[Ohlemiller 1990] analysed both unretarded cellulosic insulation and insulation having $25 \mathrm{wt} \%$ of the smoulder retardant, boric acid, added on. Boric acid was unable to halt the smoulder process but it slowed its spread by about a factor of 2 .

The strategy commonly used to analyse both flaming and smouldering combustion combines small-scale thermal analysis such as Microscale combustion calorimetry (PCFC), Thermogramivetric Analysis (TGA) and/or Differential Scanning Calorimetry (DSC) with fire reaction tests. Several medium-scale devises have been proposed by different authors [Ohlemiller 1990; Hagen 2011; Hagen 2015] to analyse the kinetics of smouldering processes.

\subsection{Mould growth resistance}

Bio-based materials have been used in construction for centuries and can last many thousands of years under proper conditions. However, they can also degrade due to the action of microorganisms such as fungi or bacteria which compromises their durability. The activity of such microorganisms depends on environment factors, mainly moisture and temperature and on the substrate characteristics such as nutrient content or hygroscopicity.

Crop by-products, like other bio-based materials, represent a potential source of nutrients for fungi and bacteria. However, under the same environmental conditions, they are not equally affected by mould growth. Their resistance against mould growth determines their suitability for application and is generally assessed in terms of critical moisture content or of the limit environment conditions from which mould growth is possible. Hofbauer et. al. [ Hofbauer 2008; Sedlbauer 2011] proposed to use an isopleth system to create a material specific profile showing at which climatic conditions (temperature and relative humidity) similar mould activity takes place. They found that bio-based materials present extremely different resistance profiles: hemp showed a rather high resistance to mould growth (similar to mineral based materials) while straw was far less resistant.

Nevertheless, the mould growth resistance of a material can be improved with the addition of biocides. Boric acid and derived salts such as borates are commonly used as biocide in some commercial insulation materials such as blowing cellulose (e.g. Homatherm flexCL, Thermaflox and Isocell cellulose insulations). Such substances have the advantage to act both as a biocide and as fire retardant and used to be considered a greener alternative to metal based fungicides, commonly used in wood preservation. However nowadays their toxicity is under evaluation and their use is limited by the European regulation and the international GHS to a concentration under 5.5\% (w/w) of the final products [ECHA 2010]. In previous work (unpublished) Lesar compared the fungal and fire resistance of cellulose insulation boards treated with boric acid and aluminium hydroxide. They used different percentages of both products and found that a mixture of $3 \%$ of boric acid and $6 \%$ of aluminium hydroxide gave the best results. The use of lactic acid bacterium may be an environmental friendly alternative to boric acid and its derivatives. The fungal inhibition action of lactobacterium has been largely studied on food products. Among the metabolites of such bacterium, lactic acid and acetic acid are often detected but it is not clear to which extend they are responsible of their antifungal activity [Schnürer 2005]. Ocallahan [O'Callahan 2012] used a lactobacillus brevis cell-free supernatant to impregnate pine wood samples and found that treated timber exhibit resistance to degradation from all fungi studied. Acid and lactic acid were detected as main metabolites of these lactobacilli. Yang [Yang 2004] found that a 1:2 dilution of L. casei supernatant inhibited growth of three mould -and one stain fungus associated with wood-based building materials. Lactic acid was identified as one of the produced metabolites, but antifungal activity was attributed to one or more unknown metabolites.

A further approach, which is gaining importance in the last few years, is the use nonbiocidal techniques for protection against fungi. Bio-based raw materials can be impregnated with water repellents, such as waxes [Lesar et al., 2011], or pre-treated to reduce their hygroscopicity. Treatments with acetic anhydride [Bledzki 2008; Karr 2000] or laccase mediated grafting are two examples of such treatments [Dong 2014; Garcia-Ubasart 2011].

\section{EXPERIMENTAL}

\subsection{Board formation}

Specimens were made using corn pith that was manually removed from corn stalks, grinded and sieved to form a 4 to 2 $\mathrm{mm}$ diameter granulate. This was then pre-treated with a $3 \%$ water solution of boric acid, aluminium hydroxide, ammonium polyphosphate, montan wax, acetic acid or lactic acid. The amount of additive incorporated (weigh, dry basis) in each specimen is shown in Tab. 1 . The pre-treated granulate was bonded with $3 \%$ of sodium alginate (weigh, dry basis) andthen, $1 \%$ of calcium sulphate dihydrate $\left(\mathrm{CaSO}_{4} \cdot 2 \mathrm{H}_{2} \mathrm{O}\right)$ was added as a source of $\mathrm{Ca}^{2+}$ ions to achieve alginate gelation. The blend was energetically stirred and was thereafter poured in a mould and hot pressed at $60^{\circ} \mathrm{C}$ for 10 minutes to a target density of $50 \mathrm{~kg} / \mathrm{m}^{3}$. The target density was achieved by controlling the grams of material (measured at room conditions, $50 \%$ relative humidity and $20^{\circ} \mathrm{C}$ ) that were introduced in the moulds. Afterwards, the specimens were dried at $60^{\circ} \mathrm{C}$ for $24 \mathrm{~h}$ and unmould. Moreover, plain samples (CA) and samples containing a larger amount of alginate (AG) were also produced. Probably due to an interaction between the binder and the acid substances, some of the specimens were weakly bonded and felt apart during their manipulation, especially those containing acetic and lactic acids. 
Tab. 1: Additives incorporated on each of the samples.

\begin{tabular}{|c|c|c|}
\hline Sample & Additives incorporated & $\begin{array}{c}\text { Amount } \\
\text { (\%) }\end{array}$ \\
\hline $\mathrm{CA}$ & - & 0.0 \\
\hline BAC & Boric acid & \multirow{7}{*}{9} \\
\hline $\mathrm{AH}$ & Aluminium hydroxide & \\
\hline AG & Alginate & \\
\hline APP & Ammon. polyphosphate & \\
\hline AA & Acetic acid & \\
\hline LA & Lactic acid & \\
\hline MW & Montan wax & \\
\hline $\mathrm{BAH}$ & Boric acid + Aluminium hydroxide & \multirow{6}{*}{$3+6$} \\
\hline BAG & Boric acid + Alginate & \\
\hline BAPP & Boric acid + Ammon. polyphosphate & \\
\hline BAA & Boric acid + Acetic acid & \\
\hline BLA & Boric acid + Lactic acid & \\
\hline BMW & Boric acid + Montan wax & \\
\hline
\end{tabular}

\subsection{Pyrolysis Combustion Flow Calorimetre}

Small-scale flammability tests were carried out on a Fire Testing Technology Pyrolysis Combustion Flow Calorimetre (PCFC). The heating rate at the pyrolyser was set to $60^{\circ} \mathrm{C} / \mathrm{min}$ up to a maximum temperature of $750^{\circ} \mathrm{C}$. Products from the anaerobic thermal degradation completed in a nitrogen atmosphere were mixed with a $20 \mathrm{~cm}^{3} / \mathrm{min}$ stream of oxygen prior to entering the combustion furnace at $900^{\circ} \mathrm{C}$. The Heat Release Rate (HRR) was determined from the oxygen consumption. Total heat release (HR) was calculated as the integral of the HRR over the complete time of the test. For each experiment a mass of $10.0 \mathrm{mg} \pm 0.1 \mathrm{mg}$ was used.

\subsection{Simultaneous thermal analysis (STA)}

Small-scale smouldering reaction heat tests were performed by simultaneous thermal analysis (STA) using a TA Instruments SDT Q600. The equipment provides simultaneous measurement of weight change (TG) and differential heat flow (DSC). Experiments were made in air, in a crucible with lid. Due to the lid, the sample was oxidized without flame because of the limitation of air penetration into the crucible. Measurements were taken out with a heating rate of $10^{\circ} \mathrm{C} / \mathrm{min}$, from $30^{\circ} \mathrm{C}$ to $900^{\circ} \mathrm{C}$. For each experiment a mass of $5 \mathrm{mg} \pm 0.5 \mathrm{mg}$ was used and the flow rate of gas was 50 $\mathrm{ml} / \mathrm{min}$.

\subsection{Medium-scale smouldering set-up}

An experimental set-up similar to the one described by Hagen et al. [Hagen 2011] was designed to determine the velocity of the smouldering front. A specimen of $40 \times 40 \times 160 \mathrm{~mm}$ was hold on top of a hot plate. Five type $\mathrm{K}$ thermocouples were placed every $3 \mathrm{~cm}$ along the vertical centerline of the sample and one on direct contact with the hot plate. In experiments, the hotplate was heated until a pre-determined temperature and it was then allowed to cool to room temperature. If the pre-determined temperature was sufficient, smouldering process initiated and the test continued until the char and ash of the sample had cooled down to less than $100^{\circ} \mathrm{C}$.

\subsection{Mould growth resistance}

In this study sealed growth jars were employed to monitor mould growth. A saturated solution of sodium sulphate $\left(\mathrm{Na}_{2} \mathrm{SO}_{4}\right)$ was used to regulate relative humidity at $97 \% \mathrm{RH}( \pm 2 \%)$ within the jars while temperature was restraint to $27^{\circ} \mathrm{C}$ $\left( \pm 0.3^{\circ} \mathrm{C}\right)$ throughout the experiment by placing the jars within a laboratory oven. Four replicate specimens of each formulation measuring $20 \times 20 \times 50 \mathrm{~mm}$ were prepared for this test. After oven drying $\left(105^{\circ} \mathrm{C} ; 2 \mathrm{~h}\right)$, the mass of the specimens was gravimetrically determined and they were placed in pairs in the growth jars. The specimens were not sterilised nor inoculated with specific fungal spores to prevent unknown changes to the substrate and to closely reproduce a real exposure situation [Thomson 2014]. Therefore, naturally occurring spores were used to determine the resistance to mould growth of the specimens. After 4 weeks of exposure, the mould growth was qualitatively determined by visual inspection with the aid of a binocular loupe, following the methodology proposed by Johansson [Johansson 2012] and quantitatively by mass loss as indicated at EN 113 [Humar 2013]. The methodology proposed by Johansson consists on a five grade rating system where 0 corresponds to "no mould growth" and 4 to "heavy growth over more or less the entire surface". The subjectivity of the method is limited as the rating process is repeated five times, each by a different and independent person. The method proposed by Johansson was used for a second run of experiments in which the mould growth by time was monitored during 42 days for the specimens that yield better results. This time, the samples were exposed to two different environments. Apart from the one mentioned above, a second sealed case was prepared in which a saturated solution of sodium chloride $(\mathrm{NaCl})$ was used to maintain the relative humidity at $75 \%$. 


\section{RESULTS AND DISCUSSION}

\subsection{Flaming combustion analysis}

The different samples presented in Tab. 1 were analysed with the PCFC technique. In this kind of microcalorimeter, the sample is heated in an inert atmosphere at a constant rate. The gasses resulting from the pyrolysis are progressively mixed with a stream of oxygen and completely combusted at the combustion furnace. Therefore, the measured heat release rate (obtained from the oxygen consumption) corresponds, strictly, to flaming combustion. The heat release rate (HRR) curves obtained in all cases had the characteristic shape of lignocellulosic materials, with a main peak around $320^{\circ} \mathrm{C}$ which is related to cellulose, a shoulder at lower temperatures related with hemicelluloses and a tail that some authors relate with lignin and other extractives [Yao 2008].
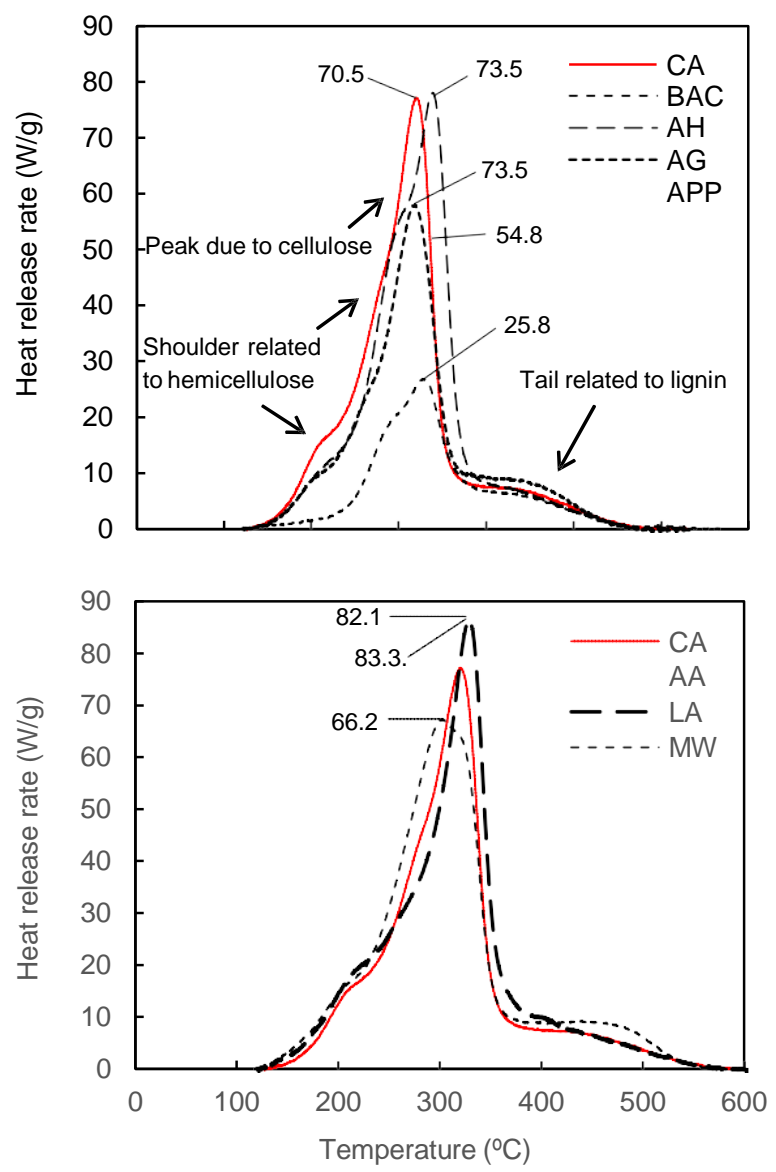

Fig. 1. Heat release rate as a function of temperature for specimens incorporating the flame retardants (top) and the fungicide additives (bottom). Results are compared with plain boards (CA).

Tab. 2: PCFC results for the insulation materials incorporating the different additives.

\begin{tabular}{lccccc}
\hline & $\begin{array}{c}\text { Total heat release } \\
\mathrm{HR}(\mathrm{KJ} / \mathrm{g})\end{array}$ & $\begin{array}{c}\text { Onset temperature } \\
\mathrm{T}_{0}\left({ }^{\circ} \mathrm{C}\right)\end{array}$ & $\begin{array}{c}\text { Temperatureatpeak } \\
\mathrm{T}_{\mathrm{PHR}}\left({ }^{\circ} \mathrm{C}\right)\end{array}$ & $\begin{array}{c}\text { Peakheatreleaserate } \\
\text { PHRR }(\mathrm{W} / \mathrm{g})\end{array}$ & $\begin{array}{c}\text { Mass loss } \\
\text { Mloss }(\mathrm{mg})\end{array}$ \\
\hline $\mathrm{CA}$ & 7.2 & 191.0 & 320.6 & 70.5 & 0.73 \\
$\mathrm{BAC}$ & 3.1 & 266.2 & 327.7 & 25.8 & 0.59 \\
$\mathrm{AH}$ & 5.8 & 218.2 & 337.8 & 73.5 & 0.67 \\
$\mathrm{AG}$ & 5.9 & 205.6 & 319.8 & 54.8 & 0.68 \\
$\mathrm{APP}$ & 6.4 & 224.9 & 334.9 & 51.8 & 0.69 \\
$\mathrm{AA}$ & 7.8 & 202.5 & 326.9 & 82.1 & 0.74
\end{tabular}




\begin{tabular}{lllccc} 
LA & 8.2 & 185.5 & 329.8 & 83.3 & 0.77 \\
MW & 8.1 & 183.9 & 308.2 & 66.2 & 0.72 \\
BAH & 7.3 & 236.6 & 332.8 & 50.0 & 0.72 \\
BAG & 4.9 & 243.2 & 325.5 & 46.4 & 0.70 \\
BAPP & 6.3 & 230.2 & 328.7 & 66.2 & 0.66 \\
WF & 9.1 & 214.6 & $249.6 / 457.0$ & $37.8 / 94.9$ & 0.74 \\
\hline
\end{tabular}

The effect of each additive on the fire behaviour of the corn pith-alginate boards is compared in Fig. 1 and Tab. 2 . Results show that specimens incorporating boric acid presented a remarkably better fire behaviour than the rest of the samples. The onset temperature $T_{0}$ (defined here as the temperature at which HRR reaches $10 \mathrm{~W} / \mathrm{g}$ ) was almost $100^{\circ} \mathrm{C}$ higher than non-treated boards as the initial shoulder was displaced to the right, the PHRR was reduced more than three times and the mass loss was lower. Alginate showed a significant improvement, in agreement with the results previously found [Palumbo 2015], although it was moderate compared with boric acid. The addition of ammonium polyphosphate resulted in a $25 \%$ reduction of the peak heat release and a displacement of the initial shoulder to the right. Aluminium hydroxide does not seem to have an important effect on the flaming behaviour of the material although the temperature at which the peak HRR occurred is slightly higher than for plain samples. On the other hand, the addition of fungicide substances had little impact on the fire reaction of the material.

The good results yield by the boric acid treatment are not surprising as it has been commonly used as fire retardant in bio-based insulation materials. However, as commented in Section 1, its use is limited in Europe to a concentration under $5.5 \%(\mathrm{w} / \mathrm{w})$. Thereafter, further specimens were made incorporating mixtures of $3 \%$ of boric acid and $6 \%$ of one of the flame retardants, in order to determine the existence of a beneficial coupled effects. The results are presented in Fig. 2 and Tab. 2. They show a general improvement of the samples incorporating aluminium hydroxide and sodium alginate when boric acid was added. In particular, the onset temperature was increased in about $45^{\circ} \mathrm{C}$, as the first shoulder is delayed, and the PHRR was reduced in $32 \%$ and $15 \%$ respectively. This contrasts with the results obtained for the ammonium polyphosphate treated samples, which showed no improvement. Indeed, although the total heat release was maintained, the PHRR of the main peak was increased, which indicates a negative coupled effect between the two substances. However, when compared to a commercial wood based insulation material (see Fig. 2), all the treated samples show a general good flaming behaviour, with a lower total heat release, a higher onset temperature and a first peak at about $80^{\circ} \mathrm{C}$ higher.

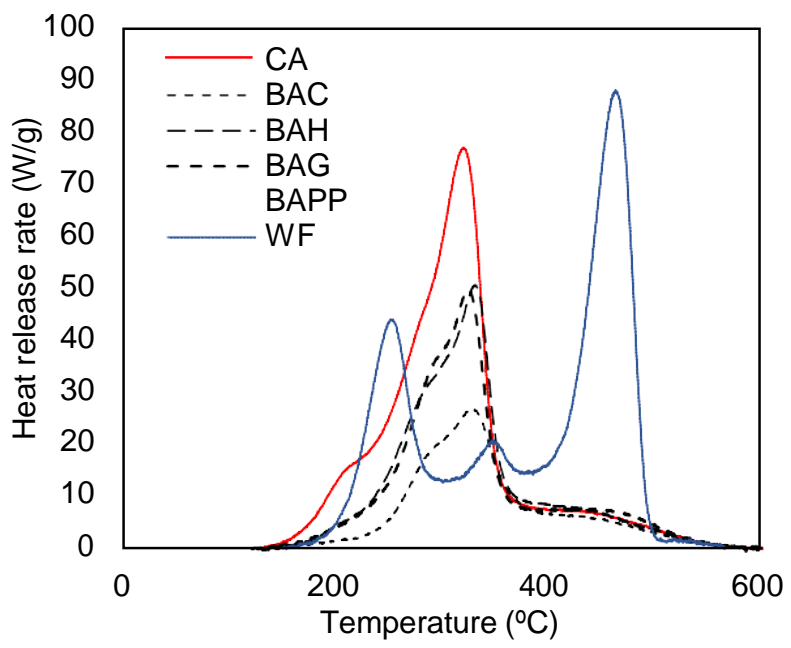

Fig. 2. Heat release rate as a function of temperature for specimens incorporating boric acid and one of the other flame retardants. Results are compared with boards containing only boric acid (BAC).

\subsection{Smouldering combustion analysis}

In previous work it was found that corn pith-alginate composites presented a remarkable propensity to smouldering combustion [Palumbo 2015]. Although fire reaction tests yielded good results, even for non-treated specimens, as they showed a self-extinguishing behaviour, after flame extinction a slow smouldering process proceeded until the complete consumption of the specimens. In order to analyse this phenomenon and its possible improvement by flame retardants, two kind of test were made, as described in section 2. At small-scale, a simultaneous thermal analysis STA was performed for the measurement of weight change (TG) and differential heat flow (DSC). These results correspond to smouldering combustion, because the tests were made in air, using a crucible with lid that limited the air penetration into the crucible. 
Fig. 3 shows the DSC curves for the untreated samples (CA) and those with boric acid (BAC). Both curves present an endothermic peak, at low temperatures, associated to water release, being a bit higher for the BAC specimen. The untreated sample had a first exothermic peak at $315^{\circ} \mathrm{C}$ associated with oxidative polymer degradation, and a second peak at $444^{\circ} \mathrm{C}$ associated with char oxidation. The addition of boric acid delayed and decreaseed the exothermic peaks. The first one appeared at $335^{\circ} \mathrm{C}$ and was reduced in about $14 \%$. The second one appeared at $515^{\circ} \mathrm{C}$ and was reduced in about $15 \%$. Results are in qualitative agreement with the results reported by Ohlemiller for cellulose insulation, although in this case the addition of boric acid caused a higher reduction in the second peak [Ohlemiller 1990]. The curve for the untreated sample is quite similar to that obtained by He et al. [He 2009] for corn stalk.

Differential thermogravimetric (DTG) results are shown also in Fig. 3 for the same samples as before. It can be observed that the shape of the DSC and DTG curves are similar, but the peaks do not occur at the same temperatures. For example, in the untreated sample the first exothermic peak (oxidative pyrolysis) for DSC appeared at $314^{\circ} \mathrm{C}$ while the corresponding DTG peak did at $273^{\circ} \mathrm{C}$. Similarly, the second exothermic peak (char oxidation) occurred at $444^{\circ} \mathrm{C}$ for DSC and at $423^{\circ} \mathrm{C}$ for DTG. These differences were also observed by He et. al. [He 2009]. The delay caused by de addition of boric acid is also clearly seen in the DTG curves, as well as the reduction in the magnitude of the first exothermic peak. However, the char oxidation peak seems to be only delayed but not reduced.

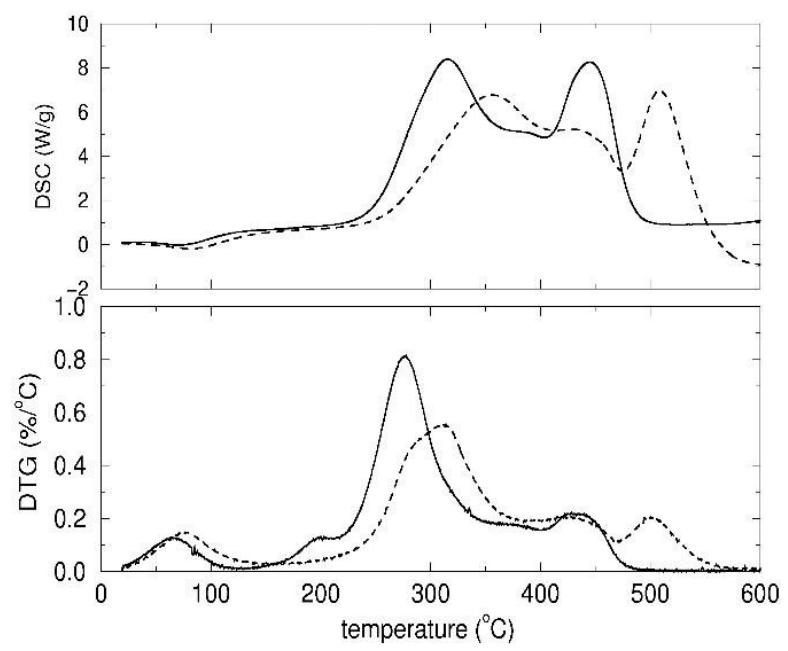

Fig. 3. DSC curves (top) and DTG curves (bottom) for untreated sample (continuous line) and sample with boric acid (dashed line).

Medium-scale smouldering tests were performed according to the device and protocol described in section 2.4. During the experiments, the evolution was visualized with an infrared camera. Temperature was recorded by 6 thermocouples located every $3 \mathrm{~cm}$ along the sample. Fig. 4 shows the infrared images in 6 different times (every 5 minutes) for untreated and boric-acid retarded samples. White colour represents the region where combustion is occurring. Red edges correspond to temperatures around $150-250^{\circ} \mathrm{C}$. A significant delay can be observed when boric acid is added. Indeed, the high temperature region seems to be smaller in extension. Fig. 5 shows the temperature recorded by the thermocouples for the same two specimens as above. The dashed lines correspond to the temperatures measured in the hotplate surface, and thus show the heating protocol: the temperature was increased up to $280^{\circ} \mathrm{C}$ in 30 min and then the hot plate was stopped and let to gradually cool down. The onset temperature was chosen as $280^{\circ} \mathrm{C}$ because in preliminary experiments it was found that this was the lowest onset temperature at which smouldering occurred. The coloured lines correspond to the temperature within the sample, which reached $550^{\circ} \mathrm{C}$ during combustion. From these curves, the speed of propagation of the smouldering front can be evaluated by determining the times at which each thermocouple position reaches a certain temperature, here chosen as $250^{\circ} \mathrm{C}$. In all the cases analysed, position and time exhibited a linear behaviour. This is shown in Fig. 6. The slopes (smouldering velocities) are shown in the inset of the figure. The velocities for the untreated samples and for samples with added alginate were very similar, but it is interesting to note that aluminium hydroxide reduced the velocity in about $30 \%$, and boric acid did in $37 \%$. The samples incorporating ammonium polyphosphate did not suffered smouldering at $280^{\circ} \mathrm{C}$, thus showing the best results. As shown in Tab. 3, these samples suffered smouldering from an onset temperature of $300^{\circ} \mathrm{C}$, the speed of propagation was reduced to $3.6 \mathrm{~mm} / \mathrm{min}$ and the average maximum temperature registered during combustion was reduced about $200^{\circ} \mathrm{C}$. 

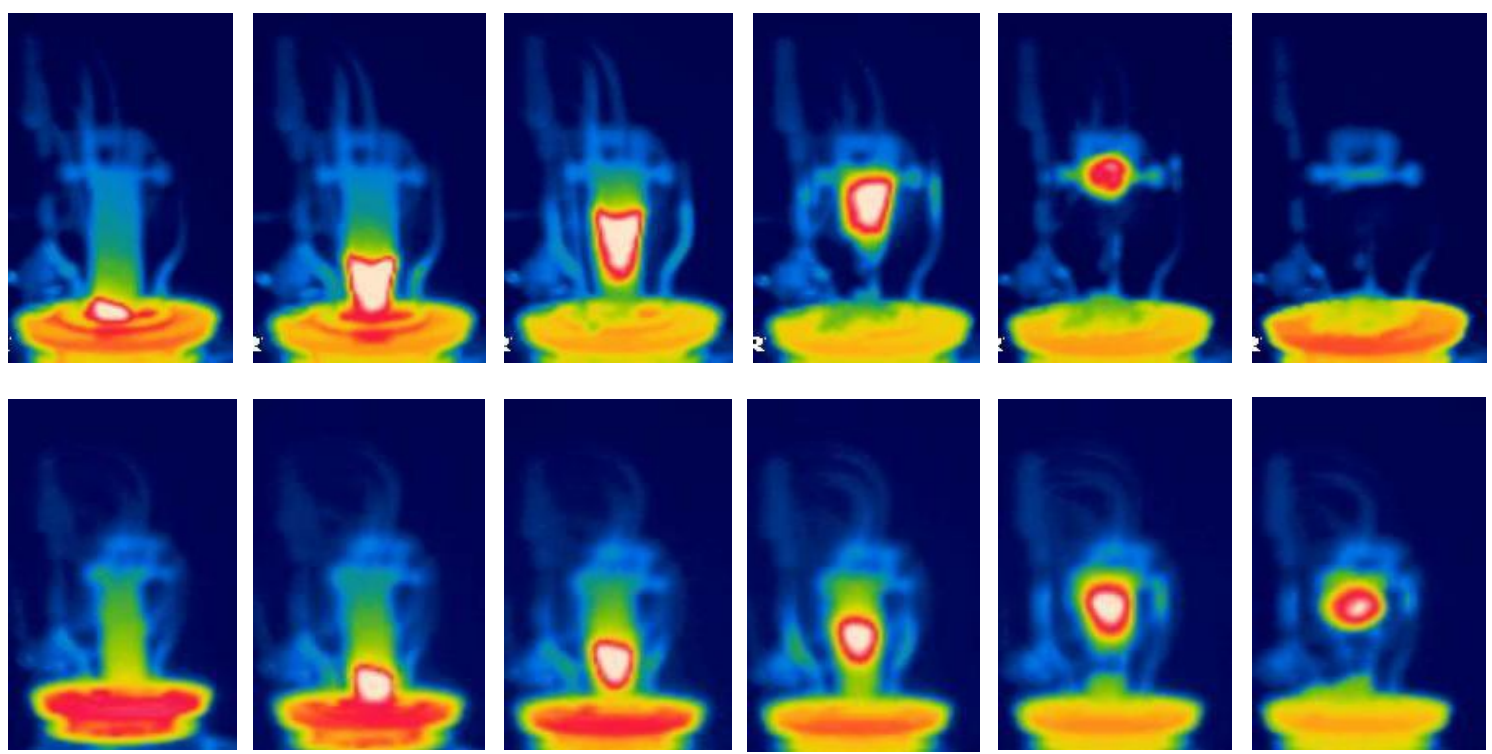

$10^{\circ} \mathrm{C}$ $400^{\circ} \mathrm{C}$

Fig. 4. Infrared images for untreated (top) and boric acid fire retarded (bottom) at times t=30, 35, 40, 45, 50 and $55 \mathrm{~min}$.
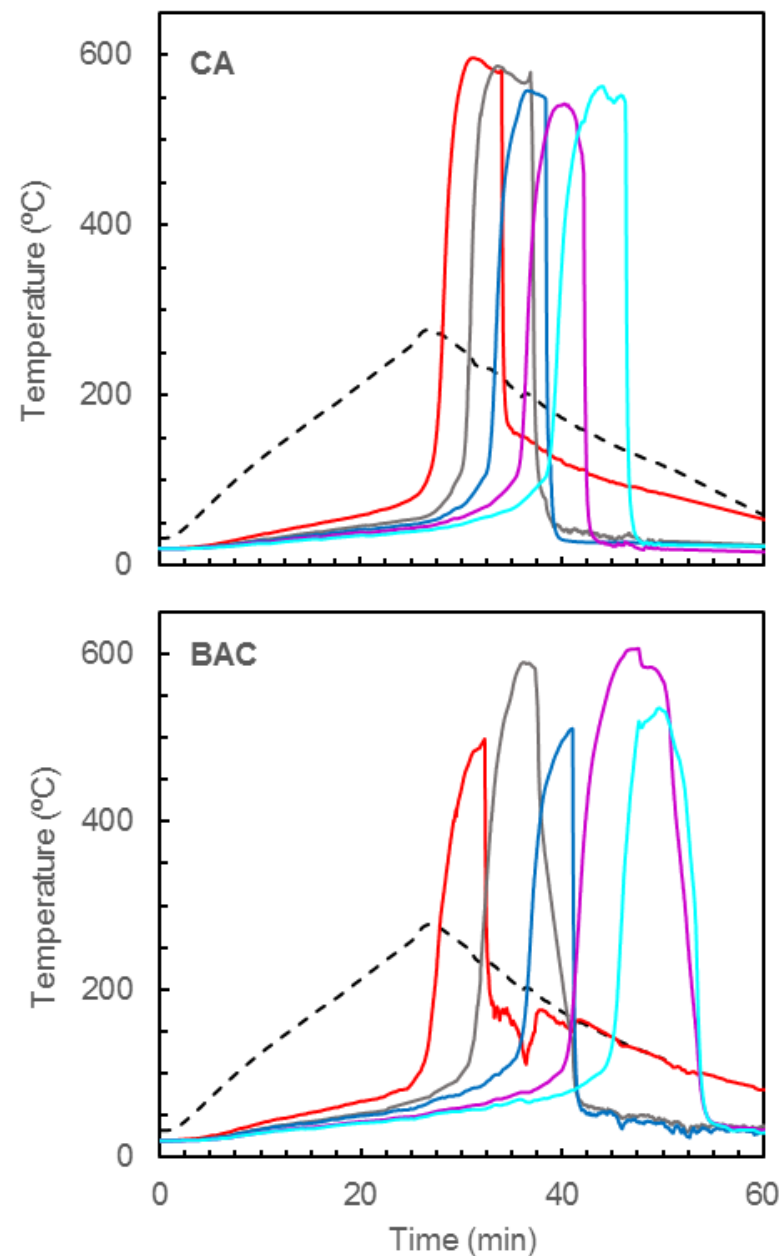

Fig. 5. Temperature evolutions for thermocouples located each $3 \mathrm{~cm}$ along the sample for untreated (top) and boric acid fire retarded specimens (bottom). 


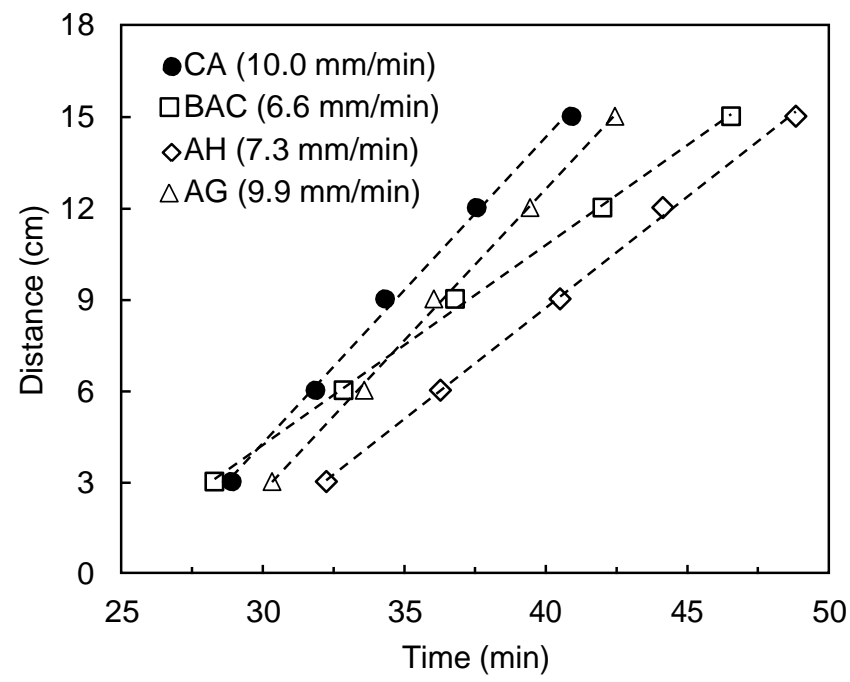

Fig. 6 Thermocouple position versus time at which temperature reaches $250^{\circ} \mathrm{C}$ for the different samples analysed. Smouldering propagation velocities (shown in the inset of the figure) are calculated as the slope of the obtained linear regressions.

Tab. 3 Effect of the treatments on the lowest combustion temperature and speed of propagation of the smouldering front.

\begin{tabular}{|c|c|c|c|c|}
\hline Sample & $\begin{array}{l}\text { Tonset } \\
\left({ }^{\circ} \mathrm{C}\right) \\
\end{array}$ & $\begin{array}{c}\text { Speed at } \mathrm{T}_{\text {onset }} \\
(\mathrm{mm} / \mathrm{min})\end{array}$ & $\begin{array}{c}\text { Average } T_{\max } \\
\left({ }^{\circ} \mathrm{C}\right) \\
\end{array}$ & $\begin{array}{c}\mathrm{R}^{2} \\
\text { (a.u.) }\end{array}$ \\
\hline CA & $\leq 280$ & 10.0 & $565 \pm 30$ & 0.997 \\
\hline BAC & $\leq 280$ & 6.6 & $545 \pm 55$ & 0.999 \\
\hline $\mathrm{AH}$ & $\leq 280$ & 7.3 & $570 \pm 45$ & 0.999 \\
\hline$A G$ & $\leq 280$ & 9.9 & $570 \pm 25$ & 0.998 \\
\hline APP & 300 & 3.6 & $355 \pm 65$ & 0.983 \\
\hline
\end{tabular}

Thereafter, further tests were performed at different onset temperatures in order to compare the performance of three different samples: samples incorporating $9 \%$ and $3 \%$ of ammonium polyphosphate (APP and APP3 respectively), and samples incorporating a mixture of boric acid and ammonium polyphosphate (BAPP). . The results are shown in Fig. 7 and Tab. 4. As expected, a lower amount of ammonium polyphosphate resulted in a more modest reduction of the speed of propagation and a lower onset temperature from which smouldering occurred. However, when the onset temperature was increased, the differences were reduced. This is clear from Fig. 7, where the behaviour of the materials at $300^{\circ} \mathrm{C}$ and $330^{\circ} \mathrm{C}$ is compared.

The sample that showed the best results was the BAPP, as the onset temperature was increased in $10 \%$ and the speed of propagation was reduced in $3.1 \mathrm{~mm} / \mathrm{min}$. Indeed, its behaviour was close to that of commercially available wood fibre insulation materials. This result indicates a positive coupled effect of the two added substances, which contrasts with the results obtained for the flaming combustion. 


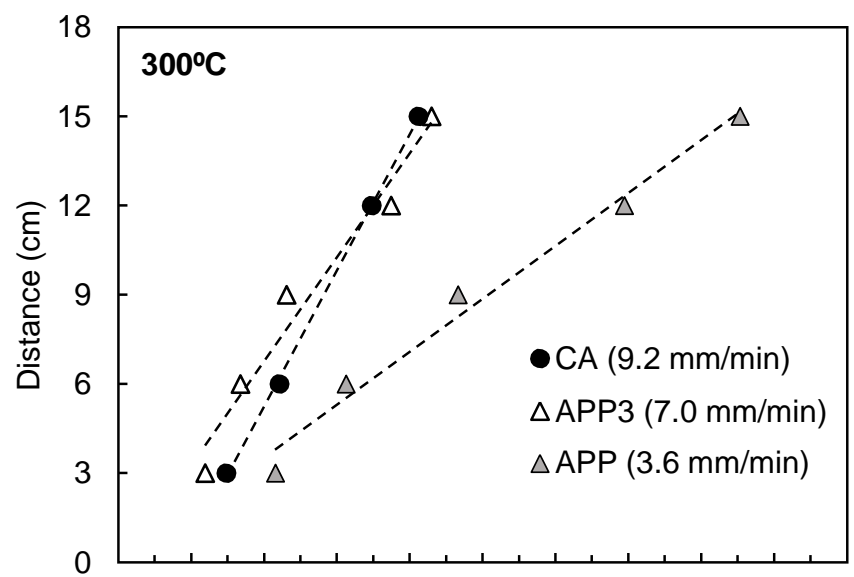

Fig. 7 Thermocouple position versus time at which temperature reaches $250^{\circ} \mathrm{C}$ for the different samples analysed. Smouldering propagation velocities (shown in the inset of the figure) are calculated as the slope of the obtained linear regressions

Tab. 4 Speed of propagation of the smouldering front $(\mathrm{mm} / \mathrm{min})$ for the different specimens at different onset

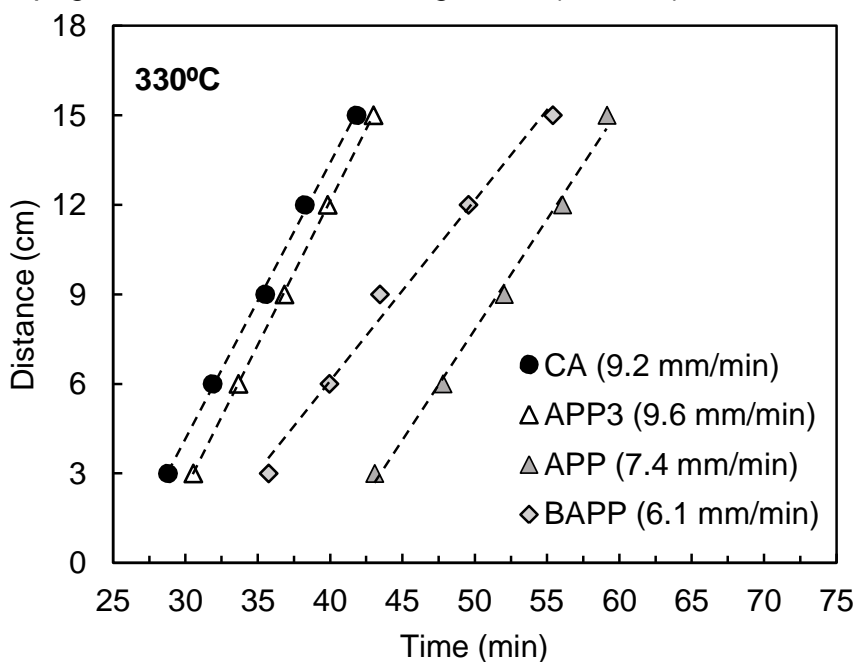

temperatures.

\begin{tabular}{lccccc}
\hline \multicolumn{1}{c}{ Sample } & $280^{\circ} \mathrm{C}$ & $290^{\circ} \mathrm{C}$ & $300^{\circ} \mathrm{C}$ & $310^{\circ} \mathrm{C}$ & - \\
\hline CA & 10.0 & - & 9.2 & - & 9.2 \\
APP3 & No smould. & 9.7 & 7.0 & $50^{\circ} \mathrm{C}$ & 9.6 \\
APP & No smould. & No smould. & 3.6 & 5.3 & 7.4 \\
BAPP & No smould. & No smould. & No smould. & 5.9 & 6.1 \\
WF & No smould. & No smould. & No smould. & No smould. & 3.2 \\
\hline
\end{tabular}

\subsection{Mould growth resistance analysis}

As mentioned in section 2.5, fungal growth was determined qualitatively and quantitatively. Qualitative assessment was based on a five grade rating system (from 0 to 4) where 0 corresponded to no mould growth and 4 to heavy growth over more or less the entire surface [Johansson 2012; Johansson 2014]. This method is a fast and effective but, as signalled by Johansson, it is somewhat subjective. In order to reduce measurement uncertainty, five people independently rated all the test specimens. It was found that differences among raters did not significantly affect the final rating, probably due to the fact that most of the specimens were severely affected by mould growth and thus rating was easy to determine. Moreover, mould decay was also determined quantitatively by mass loss. It is important to underline that, as the initial mass of each specimen was only around $800 \mathrm{mg}$, results are very sensitive to slight variation in mass. Such variations might be due to material loses during manipulation or to remnants of mycelium due to incomplete cleaning of the specimens. Nevertheless, results qualitatively agree with those obtained with the rating method and are in concordance with those presented by Humar et. al. using the same methodology [Humar 2013]. Their results indicate that, after 16 weeks of exposure, the average mass loss for cellulose insulation specimens is $0.1 \mathrm{~g} ; 0.3 \mathrm{~g}$ for hemp insulation mats and $0.83 \mathrm{~g}$ for wood fiber, which is in the same order of magnitude as the obtained values. 
Results for mould growth resistance are summarised in Tab. 5. Results show that none of the studied substances were able to prevent mould growth, except boric acid. Specimens containing $9 \%$ of boric acid experienced little fungal growth. Mould growth on these samples was rated as 1, corresponding to initial growth, and the mass loss registered was $0.02 \mathrm{~g}$. On the other cases, mould growth was rated as 4 (heavy growth over more or less the entire surface) and the mass loss registered was between 0.10 and $0.15 \mathrm{~g}$, except from CA samples, where mass loss was slightly higher (0.17 g). Thus, mixtures incorporating boric acid and one of the other substances were also tested. The results are also shown in Tab. 5. The results for the BAA mixtures are not shown as the samples felt apart before the measurements, which indicate a negative interaction between theadditive and the binder. The addition of a part of boric acid did not result in an improvement of the overall behaviour. However, it had an impact on the aspect of the fungi populations. On most of the samples a high diversity of fruits with different aspects was observed. However, on the specimens treated with boric acid, only a white filamentous structure was detected, as depicted in Fig. 8.

In the light of the results obtained, a second test was performed in order to determine the mould growth by time on samples incorporating $9 \%$ and $6 \%$ of boric acid (BAC and BAC6 respectively). In Fig. 9, the results are compared with plain samples (CA), with the raw materials separately (corn, $C$ and alginate, $A$ ) and with a commercially available wood fibre insulation (WF). Results indicate that the pith is the raw material that is more easily attacked by fungi. The addition of $6 \%$ boric acid effectively impeded the development of moulds at $75 \% \mathrm{RH}$, but not completely at $97 \% \mathrm{RH}$. However, the behaviour of treated samples was comparable, and even better than the wood fibre used for comparison.

Tab. 5: Comparative of the results obtained with the qualitative and quantitative methods. Moisture content of the samples at the end of the essay is also shown.

\begin{tabular}{lcccc}
\hline & $\Delta \mathrm{m}(\mathrm{g})$ & $\mathrm{MC} \%$ & $\Delta \mathrm{m}(\%)$ & Rating \\
\hline CA & $0.17 \pm 0.01$ & $56 \pm 6$ & $18 \pm 0.3$ & 4 \\
BAC & $0.02 \pm 0.03$ & $135 \pm 8$ & $2 \pm 3$ & 1 \\
AA & $0.13 \pm 0.02$ & $59 \pm 9 \pm 12$ & $15 \pm 2$ & 4 \\
LA & $0.13 \pm 0.01$ & $58 \pm 3$ & $16 \pm 1$ & 4 \\
MW & $0.10 \pm 0.01$ & $69 \pm 9$ & $23 \pm 7$ & 4 \\
BLA & $0.19 \pm 0.06$ & $76 \pm 7$ & $20 \pm 2$ & 4 \\
BMW & $0.15 \pm 0.02$ & 15 & 4 \\
\hline
\end{tabular}

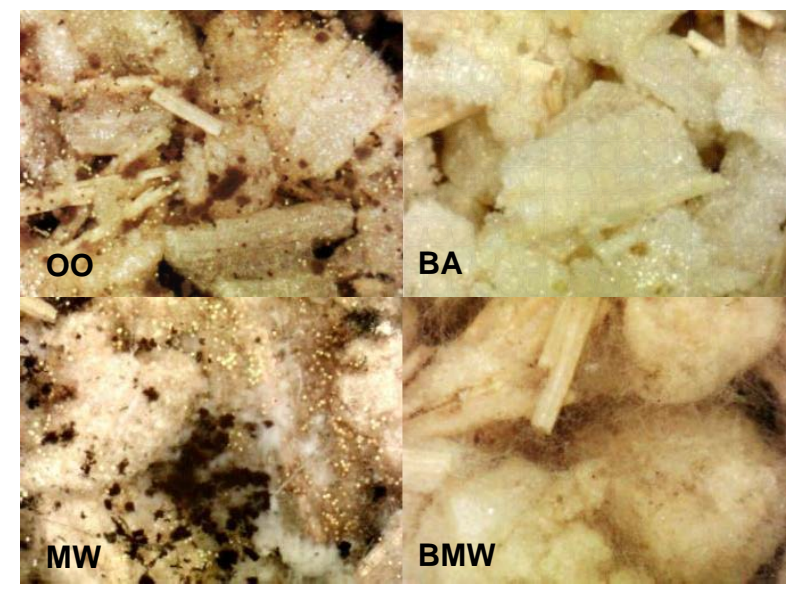

Fig. 7 Images of the mould affection of four different specimens. 

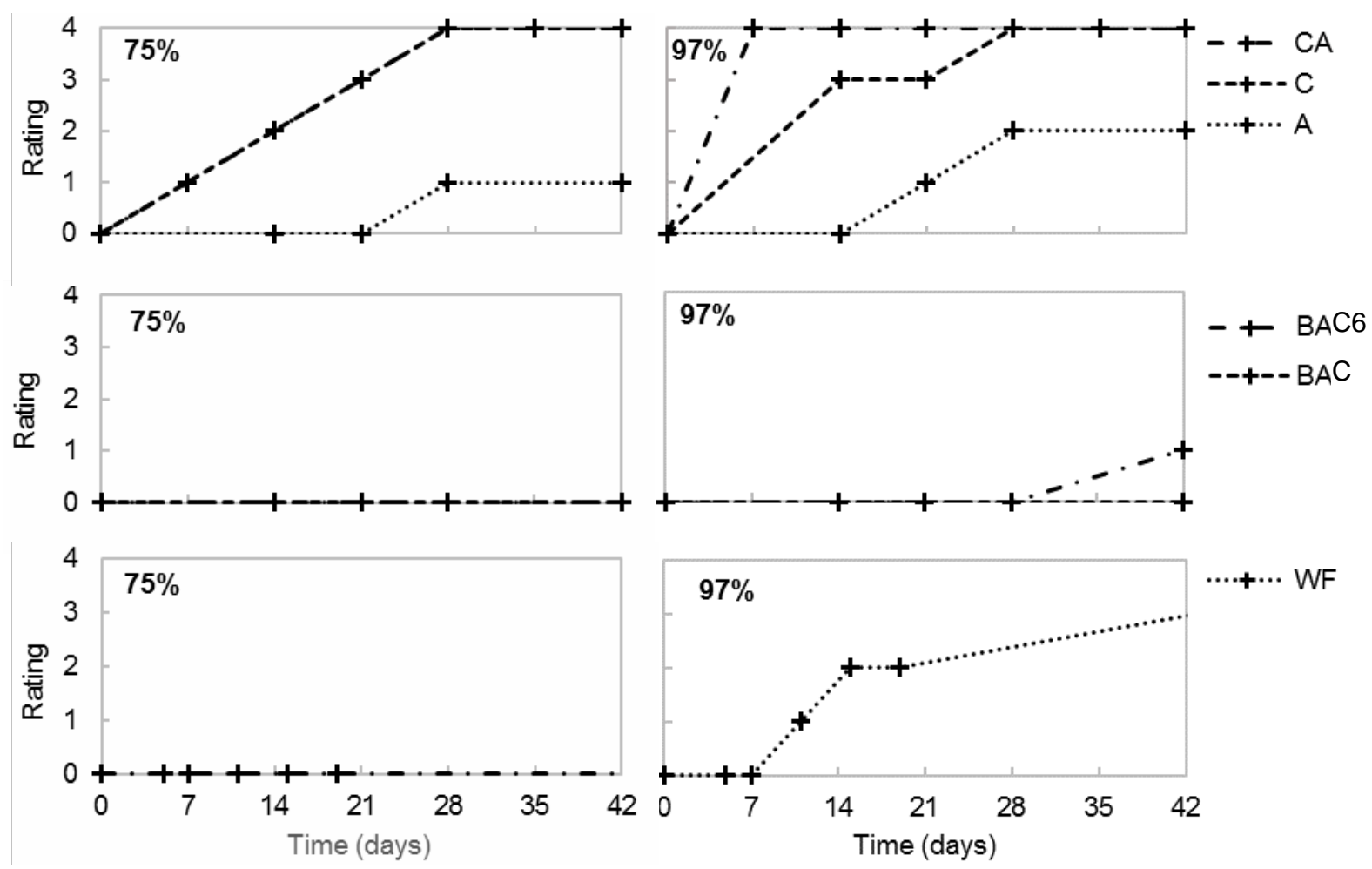

Fig. 8 Mould growth by time on untreated and boric acid treated samples. Results are compared to a commercial wood fibre insulation (WF).

\section{CONCLUSIONS}

The effect of seven different substances on the fire reaction and the fungal growth resistance of an insulation board made with corn pith aggregate and sodium alginate is evaluated. The substances were chosen for their low toxicity. Boric acid was included as it is commonly used both as fire retardant and biocide in existent bio-based insulation materials. However its use is restricted to $5.5 \%(\mathrm{~W} / \mathrm{w})$ of the final product in the European Union, as it is classified as toxic to reproduction, category 2 [ECHA 2010]. Thus, in the case of thermal insulation materials, which have a low density, the total amount of boric acid allowed is very low. In the case of the corn pith alginate materials the restriction corresponds to $2.75 \mathrm{~kg} / \mathrm{m}^{3}$.

Among the tested substances, boric acid is the one that yield the best results, in particular regarding flaming combustion and mould growth resistance. With respect to flaming combustion, all the studied parameters improve with the addition of boric acid. HR is reduced by about $50 \%$, the PHRR by about $60 \%$ and mass loss after combustion is $20 \%$ lower. Resistance against mould growth is also improved. After four weeks exposed to a very high relative humidity only marginal growth is observed which corresponds to a rating of 1 instead of 4 . Moreover, although smouldering is not prevented, the speed of propagation is reduced by almost $40 \%$.

Ammonium polyphosphate also has satisfactory results both as regards the flaming and the smouldering combustion when compared with boric acid and with a commercial wood based insulation material. Indeed, the smouldering behaviour of APP samples was better than the BAC ones. Moreover, the specimens incorporating a mixture of boric acid and ammonium polyphosphate show even better results, similar to those of the wood fibre material used for comparison, which indicates a positive coupled effect between the two substances. However, this contrasts with a reduced efficacy in flaming combustion when the two substances are mixed together. The other samples containing mixtures of $3 \%$ of boric acid and $6 \%$ of one of the other fire retardants still show an improved fire behaviour. However, this improvement is attributed mainly to boric acid.

With exception of boric acid, none of the tested biocides was able to improve the mould growth resistance of the material. Mould growth was also severe on the samples incorporating a mixture of $3 \%$ boric acid and the other biocides, but was drastically reduced when the amount of boric acid was increased to $6 \%$. The high proliferation of mould on most of the samples is not surprising, as the testing protocol was designed to expose the samples to a highly severe conditions which correspond to an exposed outdoor use. This was chosen to allow a rapid comparison and selection of 
the treatments. However, further work should be addressed in order to determine the durability of plain and treated samples in an indoor environment where this material is more likely to be used.

\section{ACKNOWLEDGMENTS}

This work is supported by MINECO (Spain) under the project BIA2014-52688-R. The authors would like to thank also Generalitat de Catalunya for the support provided under the project 2014 LLAV00031 and under a PhD studentship FIDGR.

\section{REFERENCES}

[Alvarez 2004] Alvarez VA, Vázquez A: Thermal degradation of cellulose derivatives/starch blends and sisal fibre biocomposites. Polym Degrad Stab 2004;84:13-21.

[Bledzki 2008] Bledzki a. K, Mamun a. a., Lucka-Gabor M, Gutowski VS: The effects of acetylation on properties of flax fibre and its polypropylene composites. Express Polym Lett 2008;2:413-422.

[Dong 2014] Dong A, Yu Y, Yuan J, Wang Q, Fan X: Hydrophobic modification of jute fiber used for composite reinforcement via laccase-mediated grafting. Appl Surf Sci 2014;301:418-427.

[Dorez 2013] Dorez G, Taguet A, Ferry L, Lopez-Cuesta JM: Thermal and fire behavior of natural fibers/PBS biocomposites. Polym Degrad Stab 2013;98:87-95.

[Drysdale 1998] Drysdale D: An introduction to Fire dynamics. John Wiley \& Sons Ltd œ, 1998.

[ECHA 2010] ECHA (European Chemicals Agency): Member state committee draft support document for identification of boric acid as a substance of very high concern because of its CMR properties. SVHC Support Doc 2010;1-27.

[Garcia-Ubasart 2011] Garcia-Ubasart J, Esteban A, Vila C, Roncero MB, Colom JF, Vidal T: Enzymatic treatments of pulp using laccase and hydrophobic compounds. Bioresour Technol 2011;102:2799-2803.

[Hagen 2011] Hagen BC, Frette V, Kleppe G, Arntzen BJ: Onset of smoldering in cotton: Effects of density. Fire Saf J 2011;46:73-80.

[Hagen 2015] Hagen BC, Frette V, Kleppe G, Arntzen BJ: Transition from smoldering to flaming fire in short cotton samples with asymmetrical boundary conditions. Fire Saf J 2015;71:69-78.

[He 2009] He F, Yi W, Zha J: Measurement of the heat of smoldering combustion in straws and stalks by means of simultaneous thermal analysis. Biomass and Bioenergy 2009;33:130-136.

[Hofbauer 2009] Hofbauer W, Krueger N, Breuer K, Sedlbauer K: Mould resistance assessment of building materials Material specific isopleth-systems for practical application. Indoor Air 2008;17-22.

[Humar 2013] Humar M, Lesar B: Fungicidal properties of lignocellulose insulation and building materials. Agrica 2013;34:37-45.

[Johansson 2012] Johansson P, Ekstrand-Tobin A, Svensson T, Bok G: Laboratory study to determine the critical moisture level for mould growth on building materials. Int Biodeterior Biodegrad 2012;73:23-32.

[Johansson 2014] Johansson P, Ekstrand-Tobin A, Bok G: An innovative test method for evaluating the critical moisture level for mould growth on building materials. Build Environ 2014;81:404-409.

[Karr 2000] Karr GS, Sun XS: Strawboard from vapor phase acetylation of wheat straw. Ind Crops Prod 2000;11:31-41.

[Korjenic 2011] Korjenic A, Petránek V, Zach J, Hroudová J: Development and performance evaluation of natural thermal-insulation materials composed of renewable resources. Energy Build 2011 Sep;43:2518-2523.

[Lesar 2011] Lesar B, Straže A, Humar M: Sorption properties of wood impregnated with aqueous solution of boric acid and montan wax emulsion. J Appl Polym Sci 2011;120:1337-1345.

[Madurwar 2013] Madurwar M V., Ralegaonkar R V., Mandavgane S a.: Application of agro-waste for sustainable construction materials: A review. Constr Build Mater 2013;38:872-878.

[Mohanty 2000] Mohanty AK, Khan MA, Hinrichsen G: Surface modification of jute and its influence on performance of biodegradable jute-fabric/Biopol composites. Compos Sci Technol 2000;60:1115-1124.

[Moussa 1976] Moussa NA, Toong TY, Garris CA: Mechanism of Smouldering of Cellulosic Materials; in Elsevier (ed): Symposium (International) on Combustion. 1976, pp 1447-1456.

[O'Callahan 2012] O'Callahan DR, Singh T, Mcdonald IR: Evaluation of lactic acid bacterium from chilli waste as a potential antifungal agent for wood products. J Appl Microbiol 2012;112:436-442.

[Ohlemiller 1983] Ohlemiller TJ, Lucca D: An experimental comparison of forward and reverse smolder propagation in permeable fuel beds. Combust Flame 1983;54:131-147.

[Ohlemiller 1990] Ohlemiller TJ: Smoldering combustion propagation through a permeable horizontal fuel layer. Combust Flame 1990;81:341-353.

[Palumbo 2014] Palumbo M, Navarro A, Avellaneda J, Lacasta AM: Characterization of thermal insulation materials developed with crop wastes and natural binders; in : WSB14 World Sustainable Building Conference (GBC). Barcelona, 2014, pp 1-10.

[Palumbo 2015] Palumbo M, Formosa J, Lacasta AM: Thermal degradation and fire behaviour of thermal insulation materials based on food crop by-products. Constr Build Mater 2015;79:34-39. 
[Scnürer 2005] Schnürer J, Magnusson J: Antifungal lactic acid bacteria as biopreservatives. Trends Food Sci Technol 2005;16:70-78.

[Sedlbauer 2011] Sedlbauer K, Hofbauer W, Krueger N, Mayer F, Breuer K: Material Specific Isopleth-systems as Valuable Tools for the Assessment of the Durability of Building Materials Against Mould Infestation - The " Isopleth-traffic Light "; in : XIlth International Conference on Durability of Building Materials and Components. Oporto, 2011.

[Shafizadeh 1979] Shafizadeh F, Bradbury AGW: Smoldering Combustion of Cellulosic Materials. J Build Phys 1979;2:141-152.

[Thomson 2014] Thomson A, Walker P: Durability characteristics of straw bales in building envelopes. Constr Build Mater 2014;68:135-141.

[Yang 2004] Yang V a, Clausen C a: Antifungal Metabolites of Lactobacilli. Proceeding Woodframe Hous Durab Disaster Issues 2004;307-211.

[Yao 2008] Yao F, Wu Q, Lei Y, Guo W, Xu Y: Thermal decomposition kinetics of natural fibers: Activation energy with dynamic thermogravimetric analysis. Polym Degrad Stab 2008;93:90-98. 